\title{
IMMUNIZATION OF CHICKEN BY SONICATED EIMERIA ACERVULINA
}

\author{
LILIAN, F.S. MELIKA and AL-KHATIB, R.M. \\ Veterinary Serum and Vaccine Research Institute, Abbasia, Cairo, Egypt.
}

Received: 3 May 2016; Accepted: 30 July 2016

\begin{abstract}
Through this study, sonicated sporulated Eimeria acervulina oocysts were used for chicken immunization purpose. A total number of 80 susceptible chicks were divided into four groups (A, B, C and D, 20chicks/ each), the first three groups received sonicated sporulated oocysts of Eimeria acervulina in dose of 30000, 40000 and 50000 per os /one chick respectively while group D was left without immunization as a control group. The first three groups with stand challenge test using hot strain of Eimeria acervulina and showed protection percentage of $70 \%$., $80 \%$ and $85 \%$ respectively with minimal lesion score, obvious increase body weight gain and good health condition compared with the control group which recorded high level of score lesion up to +4 with $0 \%$ protection and high mortality rate. Also there was observed reduction in fecal oocysts shedding in immunized chicks compared with the control one. On applying ELISA., it was found that there was increasing in antibody titer against Eimeria acervulina in immunized birds compared with the control group. S0 it could be corcluded that 50000 sonicated oocyct represent the best protective dose protected chicks against E.acervulina infestation.
\end{abstract}

Key words: chicks, Eimeria acervulina, sonicated sporulated oocysts, ELISA.

\section{INTRODUCTION}

Poultry coccidiosis caused by protozoan parasites of genus Eimeria has been known for over 130 years. This disease still causes great losses in poultry meat production worldwide and it is characterized by bloody diarrhea and high mortality especially at young age (Hirani and Hasnani, 2005).

The disease severity depends on both the species of the Eimeria and size of the infecting dose of oocysts. Nine types of Eimeria are distributed, one of them is Eimeria acervulina caused by protozoon of phylum Apicomplexa, genus Eimeria which cauces infection in the epithelial cells of the anterior portion of the small intestine mainly the duodenum of the chicken (Vegad, 2005). The classical clinical symptoms of coccidiosis include diarrhea tinged with blood, stunted growth, emaciation, depression, ruffled feathers, anorexia, off food, and obvious weight loss. The disease transmitted through the food, and water which got contaminated with the droppings of infected birds also rodents, cockroaches, pets, wild birds and attendants acted as a mechanical carrier of infection (Kumar, 2008). Immunization with Eimeria acervulina showed significantly decreased intestinal

Corresponding author: Dr. AL-KHATIB, R.M.

E-mail address: ragab_m10@hotmail.com

Present address: Veterinary Serum and Vaccine Research Institute, Abbasia, Cairo, Egypt. lesion score compared with control group, as the vaccine was administrated orally, the induce antibodies were principally of Ig A that protected the immune chicks from challenge (Sung et al., 2012). Sonication is the act of applying sound energy to agitate particles for various purpose (Suslick, 1990), and considered a very efficient and reliable tool for cell lysis in buffer solution (Barhami, 2006).

So the aim of this work is a trail for sonication of the sporulated oocysts of Eimeria acervulina for the immunization of young coccidia free chicks and determines its potency using challenge and serological tests.

\section{MATERIALS AND METHODS}

\section{Strain used:}

Eimeria acervulina strain used in this study was kindly provided by the Parasitological Vaccine Research Department, Veterinary Serum and Vaccine Research Institute Cairo, Egypt.

Propagation and isolation of Eimeria acervulina oocysts for experiment:

Ten young Saso chicks 7 days age, 5 chicks, each were inoculated orally by Eimeria acervulina sporulated oocysts (previously isolated through the Parasitological Vaccine Research Department, VSRI)), in a dose of 5000 oocysts / one chick, the dropping of the experimentally infected chicks were 
collected for 6 days starting from the $4^{\text {th }}$ days post infection, soaked in the water overnight and the fecal material was ground and homogenized by mortaraccording to (Dalloul et al., 2002). The oocysts were collected from the fecal samples using flotation technique, also from the predilection site of the duodenum of the experimentally infected chicks, preserved in $2.5 \%$ potassium dichromate to induce sporulation of Eimeria acervulina to be infective fig (1) then kept in refrigerator until used as described (Fatma et al., 2013). These sporulated oocysts were re-inoculated orally to another 5 susceptible chicks for the purpose of increasing the number of sporulated oocysts used for applying sonication.

\section{Experimental design:}

Eighty chicks of two weeks age were divided into 4 groups A,B, C and D. Where the $1^{\text {st }}$ three groups were inoculated orally with 30000,40000 and 50000 sonicated sporulated Eimeria acervulina oocysts respectively, while group D was kept as unimmunized control group to detect the degree of protection after challenge with 50000 sporulated Eimeria acervulina virulent strain according to (Akhtar et al., 1998) and (Jainand Archana., 2011). ELISA was carried outas a confirmatory test.

\section{Preparation of sonicated antigen:}

The sporulated Eimeria acervulina oocysts were divided into 3 groups contained 30000,40000 and 50000 oocysts, washed with phosphate buffer saline PH7.2 and then undergo concentration by centrifugation at $3000 \mathrm{rpm}$ for 20 minutes, then the sedimented oocysts were sonicated using Sonics, Materials-USA. Through ampilifiction $75 \%$ of the capacity of the apparatus three times (for 3 seconds), two minutes interval for lysis of the sporulated Eimeria acervulina, then kept in deep freeze until used for immunization purpose according to (Akhtar et al., 1998 and 2001), and (Eskander and Germin., 2013).

\section{Chicken immunization and challenge test:}

The 80 chicks of 2 weeks age were divided into four groups, A, B, C and D as 20 chicks /group and then immunized by 30000, 40000 and 50000 sonicated sporulated Eimeria acervulina oocysts per os respectively and group D was left without immunization as control group. All of the four tested groups (A,B,C and D) were challenged three weeks post immunization using 50000 sporulated oocysts virulent strain/chick as recoded by (Shirly et al., 1995 and Akhtar et al., 1998), during that time fecal samples of all immunized and challenged chicks were collected daily to detect the presence or absence of oocysts, also the dead tested birds were collected for post mortem examination for recording the degree of the infection through determining the score lesions post challenge. The score lesion were classified as follow; $\mathrm{O}$ absence of lesion, +1 white plaques like lesion containing developing oocysts were confirmed to the duodenum (Zebra striping obvious), +2 lesion much closer together (Zebra striping detected), +3 lesion numerous enough to cause coalescence with reduction in lesion size and gave the intestine the collected appearance (Zebra less obvious), +4 score lesion the mucosal wall was grayish with colonies completely coalescent striping not obvious according to (Muthusamy et al., 2011).

The survived tested chicks were slaughtered and Severity of the score lesion was recorded to determine the efficacy of the prepared vaccine as described by (Martin et al., 2007 and Amer et al., 2010).

\section{INDIRECT ELISA}

Indirect ELISA test was applied after making titration of the Eimeria acervulina phenolized antigen (sonicated sporulated oocyct). Diluted as 1:10 in sodium carbonate buffer PH 9.7. for $18 \mathrm{~h}$ at $4 \mathrm{c}$, and washed three times with PBS containing $0.05 \%$ Tween 20, Blocked with the blocking buffer as 100 $\mu 1 /$ well and incubated at $37^{\circ} \mathrm{C}$ for one hour, the serum samples after titration was used at a dilution 1:20 using anti-chicken Ig $\mathrm{G}$ whole molecule horseradish peroxides conjugate for measuring the antibody titer in the sera of the tested chicks post immunization and challenge test as recorded by (Smith et al., 1994 and Dalloul et al., 2002).

\section{RESULTS}

As shown in table (1) results of the challenge test using 50000 sporulated oocysts of the virulent strain of Eimeria acervulina revealed protection rates of $70 \%, 80 \%, 85 \%$ for groups A,B and, C respectively, while the control group D showed no protection where the chicks were dead within 7 days post challenge. In addition the degree of score lesion in groups A, B and C showed $+2,+1$ and +1 respectively, while group $\mathrm{D}$ revealed the highest score lesion +4 fig (2). Regarding the body weight gain there was increasing in the immunized three groups in comparison with the control group (D). Table (2) declared that there were no oocystsdetected in the feces of the immunized chicks through two weeks post immunization and the first three days post challenge., then began to appear, in case of group A that immunized with 30000 sonicated sporulated oocysts, the number of oocysts was 21000 oocysts / gram faces then decreased gradually to become 300 oocysts on the $15^{\text {th }}$ day after challenge test, while group B which immunized with 40000 oocysts/ chick showed that oocysts out-put was measuring 18000 oocysts in the $4^{\text {th }}$ days then decreased to 13500 oocysts in the $5^{\text {th }}$ day post challenge and decrease again to become 10500 oocysts in the $6^{\text {th }}$ day and still obviously decreased to disappear at two weeks after 
challenge. Group C which immunized with 50000 sonicated sporulated oocysts showed 16500 oocysts in the $4^{\text {th }}$ day post challenge then the number of oocysts were decreased until no oocysts were detected in the $15^{\text {th }}$ day post challenge. Unimmunized Controlchicks group D was recorded 22000 oocysts in the $4^{\text {th }}$ day post challenge to be increased to 30000,55000 and 90000 oocysts on the $5^{\text {th }}$, 6th and $7^{\text {th }}$ days respectively, then the chicks were died. Table (3) illustrated the result of ELISA, there was obvious increasing in the antibody titer of tested chicks of groups A, B and C through three weeks post immunization. They were recording on the third week post immunization as 1450, 1662 and 2255 respectively while recording 1892, 2918 and 3453 post challenge respectively, compared with the control group D which recording very low titer 210 on the $1^{\text {st }}$ week post challenge then no titer were recorded after that time because the chicks were died due to the virulence of the infection.

Table 1: Results of challenge test on young chicks immunized with sonicated sporulated oocysts of Eimeria acervulina.

\begin{tabular}{|c|c|c|c|c|c|c|c|}
\hline $\begin{array}{l}\text { Chicks } \\
\text { group }\end{array}$ & $\begin{array}{c}\text { No of } \\
\text { exp. birds }\end{array}$ & $\begin{array}{c}\text { Dose of sonicated } \\
\text { sporulated. } \\
\text { oocysts } \backslash \text { chick }\end{array}$ & $\begin{array}{c}\text { Challenge } \\
\text { dose }\end{array}$ & $\begin{array}{l}\text { No of } \\
\text { deaths }\end{array}$ & $\begin{array}{l}\text { Score } \\
\text { lesion }\end{array}$ & $\begin{array}{c}\text { Body } \\
\text { weight } \\
\text { gain }\end{array}$ & Protection $\%$ \\
\hline A & 20 & 30000 & \multirow{4}{*}{ 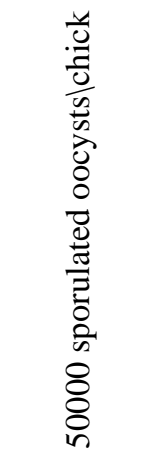 } & 6 & +2 & Increase & $70 \%$ \\
\hline B & 20 & 40000 & & 4 & +1 & Increase & $80 \%$ \\
\hline $\mathrm{C}$ & 20 & 50000 & & 3 & +1 & Increase & $85 \%$ \\
\hline $\mathrm{D}$ & 20 & - & & 20 & +4 & decrease & $0 \%$ \\
\hline
\end{tabular}

Table 2: The number of oocysts out-put of the chicks immunized with the sonicated sporulated oocysts in two weeks post immunization andchallenge.

\begin{tabular}{|c|c|c|c|c|c|c|c|c|c|c|c|c|c|c|}
\hline \multirow{2}{*}{ 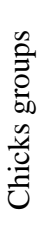 } & \multirow{2}{*}{$\begin{array}{c}\text { Dose of } \\
\text { sonicated } \\
\text { oocysts } \\
\text { /chick }\end{array}$} & \multirow{2}{*}{$\begin{array}{l}\text { No of the } \\
\text { oocysts/ } \\
\text { gram of } \\
\text { faces. } \\
\text { 1-3 days post } \\
\text { challenge }\end{array}$} & \multicolumn{12}{|c|}{ Mean No of oocysts/ gram of feaces post challenge in days } \\
\hline & & & $\begin{array}{l}4^{\text {th }} \\
\text { day }\end{array}$ & $\begin{array}{l}5^{\text {th }} \\
\text { day }\end{array}$ & $\begin{array}{c}6^{\text {th }} \\
\text { day }\end{array}$ & $\begin{array}{c}7^{\text {th }} \\
\text { day }\end{array}$ & $\begin{array}{l}8^{\text {th }} \\
\text { day }\end{array}$ & $\begin{array}{l}9^{\text {th }} \\
\text { day }\end{array}$ & $\begin{array}{l}10^{\text {th }} \\
\text { day }\end{array}$ & $\begin{array}{l}11^{\text {th }} \\
\text { day }\end{array}$ & $\begin{array}{l}12^{\text {th }} \\
\text { day }\end{array}$ & $\begin{array}{l}13^{\text {th }} \\
\text { day }\end{array}$ & $\begin{array}{l}14^{\text {th }} \\
\text { day }\end{array}$ & $\begin{array}{l}15^{\text {th }} \\
\text { day }\end{array}$ \\
\hline \multicolumn{15}{|l|}{ A } \\
\hline & 30000 & 0 & 21000 & 19800 & 15000 & 12000 & 9000 & 6600 & 6000 & 4200 & 2100 & 1200 & 600 & 300 \\
\hline \multicolumn{15}{|l|}{ B } \\
\hline & 40000 & 0 & 18000 & 13500 & 10500 & 9600 & 7200 & 5100 & 3900 & 2400 & 1500 & 900 & 300 & 0 \\
\hline \multicolumn{15}{|l|}{$\mathrm{C}$} \\
\hline & 50000 & 0 & 16500 & 12600 & 7200 & 5400 & 4200 & 3000 & 2100 & 1800 & 1200 & 900 & 300 & 0 \\
\hline D & - & 0 & 22000 & 30000 & 55000 & 90000 & & & & Birds & died & & & \\
\hline
\end{tabular}


Table 3: Mean ELISA titer of immunized and challenged chicks against Eimeria acervulina

\begin{tabular}{lcccccc}
\hline \multirow{2}{*}{\begin{tabular}{l} 
group \\
\cline { 2 - 6 }
\end{tabular}} & \multicolumn{2}{c}{ Post immunization } & \multicolumn{4}{c}{ Post challenge } \\
\hline A & $1^{\text {st }}$ week & $2^{\text {nd }}$ week & $3^{\text {rd }}$ week & $1^{\text {st }}$ week & $2^{\text {nd }}$ week & $3^{\text {rd }}$ week \\
\hline B & 642 & 1023 & 1450 & 1345 & 1578 & 1892 \\
\hline C & 982 & 1272 & 1662 & 1662 & 2120 & 2918 \\
\hline D & 1039 & 1782 & 2255 & 1862 & 2502 & 3453 \\
\hline & 65 & 85 & 95 & 210 & dead & dead \\
\hline
\end{tabular}

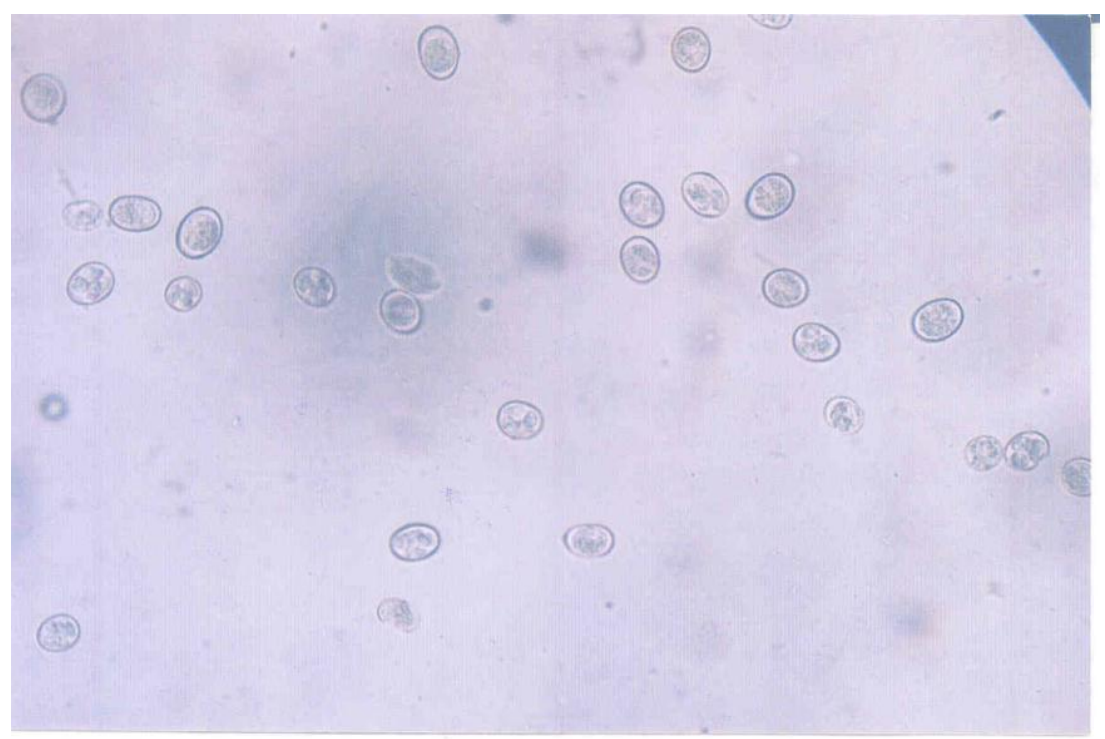

Fig. 1: Sporulated oocysts of Eimeria acervulina isolated from the fecal samples 40x

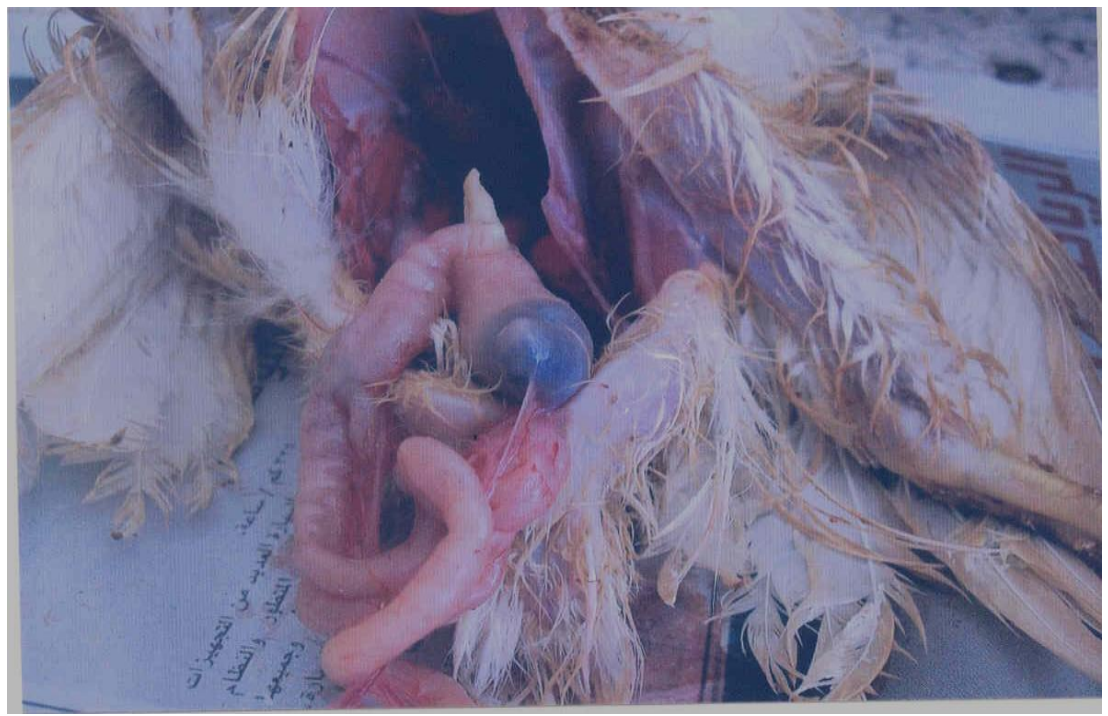

Fig. 2: Score lesion +4 : The duedenum of control chicks showed grayish mucosal wall. 


\section{DISCUSSION}

Induction defense against avian coccidiosis is one of the most important object for improving poultry industry in our country as a result of the great loss in national economy due to the high rate of mortality in poultry farms through the infection by coccidiosis in general. Trial for immunizing young chicks in the early age to avoid the spread of the infection in large scale is a very good target. Eimeria acervulina is considered a moderately harmful coccidia, and cause reduction in the rate of weight gain, reducing of egg production in laying hens, meanwhile heavy infection causes high mortality (McDonald and Ballingll., 1983).

Although using attenuated live vaccine mainly useful for vaccination against coccidiosis but it had some disadvantages in the vaccinated birds as short duration of immunity as stated by Champman et al. (2005). Using sonication for immunization purpose is easy, and give satisfied results on the tested chicks. There were no local lesion detected and no undesirable reactions were observed in the tested birds. Also there were no negative responses in feeding consumption and body weight gain. The immunized young susceptible chicks showed absence of any systemic reactions so the use of sonicated sporulated Eimeria acervulina for immunization is safe in agreement with (Akhtar et al., 2001) whoused sonicated coccidial oocysts protection $\%$ were $70 \%$, $80 \%$ and $85 \%$ in groups $\mathrm{A}, \mathrm{B}$, and $\mathrm{C}$ respectively as recorded in table (1) with normal increase in the body weight of the tested chicks, the number of oocysts out- put in the immunized chicks showed obvious decrease compared with the control group $D$, this result agrees with those of (Ziomko et al., 2005 and Lilian et al., 2014) who stated that the number of oocysts out- put was reduced in the vaccinated birds compared with unvaccinated control birds as tabulated in table (2). On applying ELISA for measuring the mean antibody titer against Eimeria acervulina as showed in table (3), it was found that there was obvious increasing in the titer in the immunized chicks compared with the control one and this result parallel to those of Davis et al. (1985) and Eskander and Germin. (2013) who prepared attenuated Eimeria tenella anti coccidial vaccine and found that there was high antibody titer of Eimeria tenella in the sera of vaccinated chicks compared with unvaccinated control group. The sonication of the sporulated Eimeria acervulina oocysts lead to production of mucosal cell membrane immune response against the infestation by Eimeria acervulina as recorded by Holmgran and Czerkinsky. (2005). Although there was no significant differences between the groups of chicks A,B and $\mathrm{C}$ either in case of oocysts out-put or mean antibody titer produced but there was obvious of varying degrees in the percentage of protection between the three groups recording $70 \%, 80 \%$ and $85 \%$ respectively.

\section{CONCLUSION}

Administration of sonicated sporulated Eimeria acervulina oocysts as immunogens for raising the immunity of young chicks against challenge with this type of Eimeria proved that it was efficient, safe, has no post vaccinal reaction, easy in preparation and cheap. The immunized chicks showed good health condition with normal increasing in body weight gain compared with the control group. So using the sonicted sporulated oocysts for immunization against Eimeria acervulina could be used successfully.

\section{REFERENCE}

Akhtar, M.; Ayaz, M.M.; Hayat, C.S. and Ashfaque, A.M. (1998): Immune responses of sonicated coccidial oocysts in chicken. Pak. J. Biol. Sci,1(4): 389-391.

Akhtar, M.; Hayat, C.S.; Ashfaque, A.M.; Ayaz, M.M. and Hussain, I. (2001): Development of immunology to coccidiosis in chicken administrated sonicated coccidial vaccine. Pak. Vet. J., 21(2): 61-64.

Amer, M.M.; Awaad, M.; Rabad, M.; Dablam, T.N.; Mghetas, M. and Kutkat, M.A. (2010): Isolation and identification of Eimeria from coccidiosis in chicken. J. Amer Scin. 6(10): 1107-1114.

Barhami, A.M. (2006): Immune response of chicken to an experimental sonicated coccidian oocysts vaccine. Archives of Razi Institute 61(1): 4348.

Champman, H.D.; Robert, B.; Shirly, M.W. and William, R.B. (2005): Guideline for evaluating the efficacy and safety of live anticoccidial vaccines, and obtaining approval for their use in chicken and Turkeys. Avian Pathol., 34(2): 279-290.

Dalloul, R.A.; Lillehoj, H.S.; Shellem, T.A. and Doerrr, H.A. (2002): Effect of vitamin A deficiency on host intestinal immune response of Eimeria acervulina in broiler chickens Poultry science 81: 1509 -1515.

Davis, P.J.; Barrat, MJ.; Morgan, M.; Pafry, S.H.; Mec Donold, L.R. and Joyner, L.P. (1985): Immune response of chicken to oral immunization by trickle infection with Eimeria. Research in avian coccidiosis. Proc, Georgia coccidiosis conf. 11. P: 618-633.

Eskander, N.B. and Germin, S.S. (2013): Attenuation of Eimeria tenella by Precocious line. Zag, Vet. J. 41 (3)1524-1530.

Fatma, M.Y.; Hala, A.A. and Afat, A.E. (2013): Clincopathological studies on the effect of Artemisia cina (Sheih Baladi) on coccidiosis in 
chicken. Porc. $6^{\text {th }}$ Conf. Vet. Res., NCR, Cairo, Egypt, p 1-14.

Hiriani, N.D. and Hasnani, J.J. (2005): Effectes of season and age on the prevalence of fowl coccidosis. Indian J. Field Veterinarians, 1(2): 35-38.

Holmgran, J. and Czerkinsky, C. (2005): Mucsal immunity and vaccines. Nature Medicine Supplement (11): 545 -553.

Jain, P.C. and Archana, J. (2011): 'Diagnosis' General veterinary parasitology. P 182-183.

Kumar, S.D. (2008): Poultry production "Protozoal Disease" coccidiosis p: 179-182.

Lilian, F.S.; Melika, AL-Khatib, R.M. and Romany, M.M. (2014): Propagation and attenuation of Eimeria acervulina. EVMSPJ, 10: 41-50.

Martin, W.; Shirly, M.W.; Smith, L. and Blake, D.P. (2007): Challenge in the successful control of the avian coccidian. Vaccine, 25: 5540-5547.

MCdonald, V. and Ballingll, S. (1983): Further investigation of the pathongenicity, immunogenicity and stability of precocious Eimeria acervulina. Parasitology, 86: 361-369.

Muthusamy, R.; Sansudeen, S.B.; Sankaralingam, G. and Gopal, D.R. (2011): Lesion scoring technique for assessing the virulence and pathogenecity of Indian field isolates of Eimeria species. Veterinarski 81(2): 259-271.
Shirly, M.W.; Bushell, Y.E.; McDonald, V. and Stromberge. (1995): Alive attenuated vaccine for control of avian coccidiosis in broilor breeders. Vet. Res., 137; 453-457.

Smith, N.C.; Wallach, M.; Miller, M.D.; Morgenstern, R.; Braun, R. and Eckert, J. (1994): Maternal transmission of immunity to Eimeria maxima: Enzyme Linked Immunosorbant Assay analysis of protective antibodies induced by infection. Infect, Immun. 4: 1384-1357.

Sung, H.L.; Hyun, S.L.; Jang, S.L.; Kyung, W.L.; Duk, K.K.; Erik, P.L.; Robert, J.Y. and Paul, J.D. (2012): Evaluation of novel adjuvant Eimeria profilin complex on intestinal host immuneresponse against live E. aervulina challenge infection. Amer. Assoc. Avi. patholg., (56): 402-405.

Suslick, K.S. (1990): "Sonochemistry" Science, 247: 1439-1445.

Vegad, J.L. (2005): "Protozoal Diseases" Poultry disease; A guide for farmers andpoultry professionals" Chapter 17: 189-199.

Ziomko, I.; Jacek, K.; Cencek, T.; Gornowicz, E.; Aleksander, S. and Ashash. (2005): Prevention of broiler chick coccidiosis using inactivated subunit vaccine coxabic. Bull Vet. Inst. Pulawy 49, 299-302.

\section{تحصين الاجاج ضد الايمريا اسرفيولينا المعالج بالموجات الصوتية

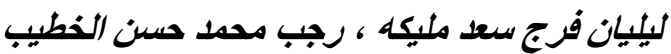

E-mail address: $\underline{\text { ragab_m10@hotmail.com Assiut University web-site: } \underline{w w w . a u n . e d u . e g}}$

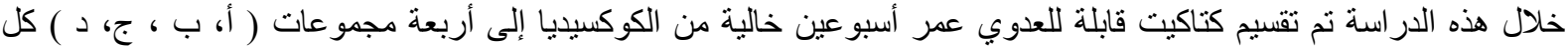

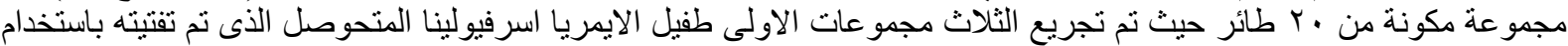

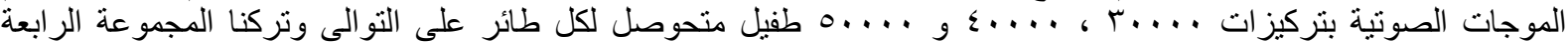

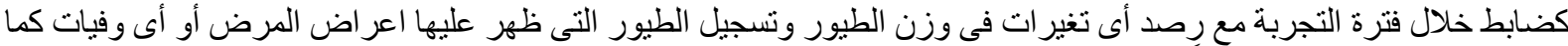

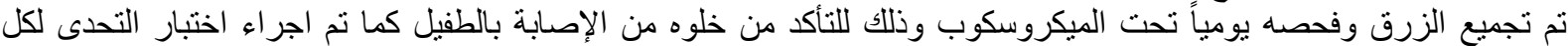

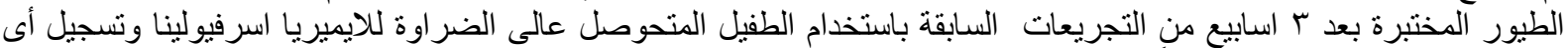

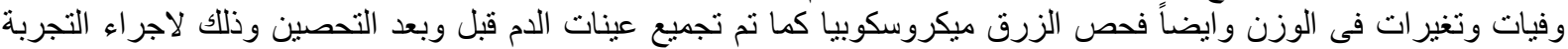

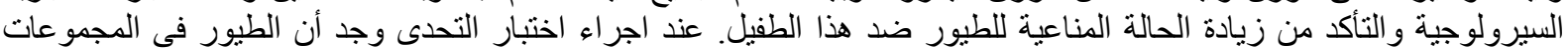

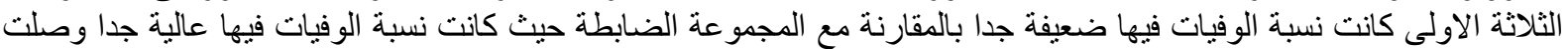

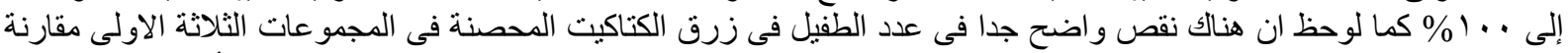

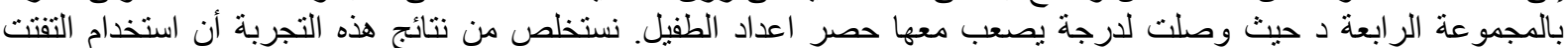

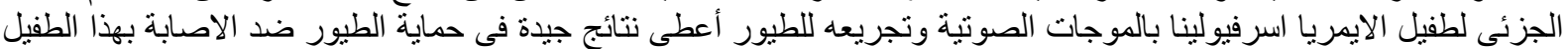

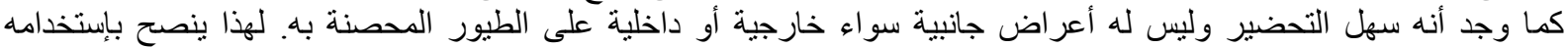
لتحصين الطيور ضد الإصابة بطفيل الأيمريا اسرفيولينا. 